\title{
Pavement and Noise Reduction Performance of Open-Graded Asphalt Friction Course Improved by Waste Tire Crumb Rubber
}

\author{
Ya Wang $\mathbb{D}^{1}{ }^{1}$ Xianguang Wang, ${ }^{2}$ and Liwen Zhang $^{1}$ \\ ${ }^{1}$ Institute of Design and Management, China Construction Eighth Engineering Division Co.,Ltd., Shanghai 201206, China \\ ${ }^{2}$ China Academy of Transportation Science, Beijing 100029, China \\ Correspondence should be addressed to Ya Wang; wy21th@163.com
}

Received 7 June 2021; Revised 23 August 2021; Accepted 28 August 2021; Published 9 September 2021

Academic Editor: Belén González-Fonteboa

Copyright (c) 2021 Ya Wang et al. This is an open access article distributed under the Creative Commons Attribution License, which permits unrestricted use, distribution, and reproduction in any medium, provided the original work is properly cited.

To further reveal the road performance and noise reduction performance of open-graded friction course (OGFC), the crumb rubber prepared by adding waste tires were considered, and the performance requirements of the material were put forward. To avoid the influence of rubber particle swelling on aggregate, the special gradation and mix proportion of OGFC mixture were designed, and the particle size of $4.75 \mathrm{~mm}$ was proposed as the control size. The test results show that the aggregate forms a good embedded structure. The resilient modulus, deformation performance, and fatigue performance of R-OGFC asphalt mixture with different crumb rubber contents were studied. According to the test results, the rubber particle content under the best road performance and noise reduction effect was proposed. The results show that, after adding a certain amount of crumb rubber, the performance of asphalt mixture has been greatly improved, especially the dynamic stability has been improved by $84 \%$. Although the resilient modulus has decreased by $10 \%$, the creep performance has decreased by $37 \%$, and the fatigue life has decreased by $31 \%$ ( $2 \%$ rubber content), the noise reduction can reach $3.6-8.6 \mathrm{~dB}$, and the noise reduction performance is significant. This shows that the best content of rubber particles is between $1.5 \%$ and $2 \%$, and the R-OGFC mixture modified by rubber has a good application prospect.

\section{Introduction}

With the rapid increase of the number of motor vehicles [1], the noise and waste tire problems caused by it affect the urban environment more and more. Therefore, the noise reduction technology of grinding waste tires into rubber powder $[2,3]$ applied to the road has been greatly developed.

The technology of crumb rubber used in asphalt pavement is mainly divided into wet process [4] and dry process [5]. The wet process is to modify the base asphalt with crumb rubber, while the dry process is to mix crumb rubber with aggregate and then add asphalt to prepare mixture. Although the dry process often leads to unstable road performance and pit, crack and other diseases arise due to improper mix design. However, compared with the wet process, the dry method has the advantages of simple construction process, more rubber powder, higher utilization rate of waste tires, and better high temperature stability, so it has been widely concerned.

The research on the noise reduction mechanism of rubber asphalt pavement has two aspects: one is the characteristics of crumb rubber itself and the change of physical characteristics of asphalt mixture; the other is the research on the gradation of mineral aggregate. Rubber itself is a kind of high molecular polymer; its high viscoelasticity and damping properties can play a role in attenuation of sound wave propagation [6]. Philip [7] found that adding carbon fiber into rubber can reduce noise by $17-24 \mathrm{~dB}$ in the range of $7-12 \mathrm{kHz}$. Wu [8] analyzed the influence of material thickness, flow resistance, and air layer thickness on the sound absorption performance of two kinds of rubber materials and considered that the sound absorption performance of metal rubber single-layer sound absorption structure could be effectively improved by optimizing the above parameters. For rubber asphalt pavement, crumb 
rubber and asphalt are ideal damping materials, which have good vibration and noise reduction effect. When the vehicle is driving on the road, the vibration will be transmitted to the damping material of the road, causing the internal displacement and friction of the damping material, thus consuming a lot of vibration energy. At the same time, the rubber asphalt pavement has greater deformation than the traditional pavement, which also stores part of the energy. When the wheel leaves, the deformation recovers, thus releasing the stored energy. Wang [9] conducted tire vertical free fall vibration attenuation test with two kinds of modified asphalt mixture track board specimens. It was found that the damping ratio and loss factor of crumb rubber-modified asphalt mixture specimens were about 5 times larger than that of SBS-modified asphalt mixture, and the amplitude of free vibration attenuation was larger, crumb rubber-modified asphalt mixture had better damping characteristics and noise reduction function. Cao [10] also found that the elasticity and damping properties of the pavement were enhanced by adding a certain amount of waste tire rubber particles into the asphalt mixture. The pavement had the function of reducing tire pumping noise and damping noise reduction. Bueno [11] added waste tire rubber particles into asphalt pavement, evaluated the vibration reduction effect, and considered that crumb rubber asphalt pavement had greater porosity, so it had a good noise reduction effect. Chandran [12] compared the specimens made of three sizes of rubber particles, and the results showed that the specimens mixed with large size of rubber particles had better damping performance and damping characteristics.

In addition, through the design of mineral aggregate gradation type of asphalt mixture, the purpose of noise reduction can also be achieved. Meiarashi [13] compared porous drainage pavement with dense-graded asphalt pavement; the results showed that the noise of vehicles was reduced by $2.0-7.0 \mathrm{~dB}$. Kehagia [14] also found that densegraded rubber asphalt pavement was better than ordinary asphalt pavement in reducing noise, which can reduce noise by about 1 3dB. Yang [15] compared the sound absorption coefficient of SMA pavement and other asphalt pavements and the vibration performance of pavement and tire system and found that the gap-graded asphalt mixture had better sound absorption performance than the dense-graded asphalt mixture pavement, and the noise absorption was about $0.7 \mathrm{~dB}$. It can be seen that the texture depth, air void, and other factors have a significant impact on the noise reduction effect. The sound absorption effect of open-graded mixture is better than that of gap-graded mixture, while the densegraded mixture is the worst. However, too large void ratio will lead to the decrease of pavement mechanical properties. The service life of pavement can be effectively increased by using modifier such as waste rubber powder, increasing the number of polar functional groups of crumb rubber and improving the bonding ability and roughness between asphalt and aggregate [16]. For example, Poovaneshvaran [17] modified asphalt with crumb rubber and natural rubber and tested the rheological properties, bonding properties, and shear resistance under different conditions. The test results showed that rubber asphalt had better elastic recovery performance, the adhesive strength of rubber powdermodified asphalt binder was better, and the shear resistance of natural rubber-modified asphalt binder was better. Hainin [18] used a variety of mineral additives to replace cement to test the performance of concrete and found that the concrete pavement with $5 \%$ and $10 \%$ replacement level showed good performance and strength. Moreno [19] studied the effects of digestion time (contact time between crumb rubber and asphalt) and crumb rubber dosage on the mechanical properties of the mixture and believed that the increase of crumb rubber would lead to the increase of asphalt quantity, and the mixture would become loose. When the amount of rubber powder was less than $1 \%$ and the digestion time was 90 minutes, the mechanical properties of the mixture were the best. Yu [20] used quantitative rubber powder to replace the same volume of aggregate in the mix design of dry process rubber asphalt. It was found that when the crumb rubber powder content was $5 \%$ (volume ratio), the antidispersion performance of the mixture was the best, while when the rubber powder content was 3\% (volume ratio), the dynamic stability of the mixture was the highest. Ren [21] prepared RPMA pavement with waste rubber as a binder and compared it with SBS-modified asphalt mixture. It was found that RPMA pavement had advantages in high-temperature stability and water stability, while fatigue performance was close to SBS-modified asphalt mixture, and crumb rubber-modified asphalt had good road performance. Bennert [22] found that OGFC pavement with crumb rubber had better noise reduction effect than OGFC pavement without crumb rubber. Through long-term observation, Tehrani [23] found that the noise reduction effect of densegraded rubber asphalt pavement could be maintained for more than 6 years, while that of ordinary hot mix asphalt pavement was at most 4 years and that of open-graded asphalt mixture was less.

Previous studies focused on the mechanical properties of mixture or the effect of noise reduction. To make the rubber asphalt pavement play a greater role and improve the environmental quality, it is necessary to improve the service life of the pavement as much as possible on the premise of ensuring the function of noise reduction and vibration reduction. The porosity of open-graded asphalt mixture is larger, although it is not as good as gap-graded asphalt mixture in mechanical properties; it has better noise reduction effect. On the premise of ensuring a certain air void, adding crumb rubber can improve the performance of the mixture. The purpose of this paper is to evaluate the technical performance of open-graded asphalt mixture (ROGFC) modified by dry process rubber. The volume substitution method is used for mix design. The high temperature performance, water stability, elastic performance, deformation performance, and fatigue performance of the mixture are tested, and the road performance of rubber asphalt is analyzed. At the same time, through indoor vibration test and field test, the vibration and noise reduction characteristics of rubber asphalt pavement with different crumb rubber contents are studied. Through the above research, it can provide some reference for the design of rubber asphalt pavement. 


\section{Test and Methods}

The technical roadmap of this paper is shown in Figure 1.

\subsection{Raw Materials}

2.1.1. Crumb Rubber. Due to the characteristics of high elasticity and high elongation, crumb rubber should be used as fine aggregate to fill asphalt mixture. Therefore, the size of rubber particles should not exceed $4.75 \mathrm{~mm}$, and $1-3 \mathrm{~mm}$ rubber powder is generally used. As a part of aggregate, the shape and hardness of rubber have a great influence on the strength and stability of asphalt mixture. Considering the large dispersion of waste tires, the main technical performance requirements of rubber particles are proposed and tested. The results are shown in Table 1.

To give full play to the high elastic properties of rubber and make the designed dry process rubber asphalt mixture have good performance, the coarse rubber particles are used in this test. Rubber particles are made of waste tires crushed at room temperature. The apparent density is $1.14 \mathrm{~g} / \mathrm{cm}^{3}$, and its shape is shown in Figure 2(a), and the white matter is the uncoated fiber. It can be seen that the rubber particles have high fiber content, coarse particle size, smooth surface, and poor affinity with asphalt. Therefore, the rubber particles should be treated. The waste rubber of tire will undergo strong shear and oxidation during crushing, and the surface of waste rubber will produce acid groups, that is, the surface of the rubber particles has certain acidity. However, when asphalt contacts with acid materials, it is not easy to form chemical adsorption. The interaction between molecules is only the physical adsorption of van der Waals force, and it is reversible. Therefore, the adhesion force produced by this physical adsorption is much weaker than that of chemical adsorption, which will directly affect the performance of the mixture. The low viscosity oil containing a small amount of asphalt is mixed with rubber particles to make rubber particles absorb certain oil content in advance. The treated rubber particles are rough in surface, dark in color, and free of fiber, as shown in Figure 2(b). Figures 2(c) and 2(d) are the microtexture before and after treatment, and it can be seen that the roughness of rubber particles increases significantly after treatment.

2.1.2. Asphalt and Aggregate. In this paper, the matrix asphalt is Donghai 70 \# asphalt (Table 2), the coarse aggregate is diabase, the fine aggregate is limestone, and the mineral powder (Table 3 ) is made of high-quality limestone. The raw materials used meet the requirements of JTG F40-2004 Technical Specification for Construction of Highway Asphalt Pavements.

2.1.3. Aggregate Gradation. According to the Mohr-Coulomb theory [24], the mechanical strength of asphalt mixture is composed of the internal friction between mineral aggregate particles, the cohesive force between asphalt and aggregate, and the cohesive force of asphalt. The OGFC mixture is a typical skeleton void structure, where a certain amount of crumb rubber is added, filling some voids between coarse aggregate, making it develop toward dense structure, and theoretically improving the antiaging performance to a certain extent.

Because the rubber particles appear swelling in the mixture, the volume of rubber particles expands, and the expansion process will be intensified with the increase of road temperature, so it is easy to cause the increase of the air void of the mixture and affect the performance of the mixture. The air void of OGFC is large, mainly coarse aggregate, which generally accounts for about $80 \%$, while fine aggregate only accounts for about $20 \%$. Therefore, the key of OGFC structure is to form a skeleton embedded structure, so as to ensure large voids and sufficient pavement strength. The key mesh size is $2.36 \sim 4.75 \mathrm{~mm}$.

According to a large number of tests, when APA, $100 \mathrm{kN}$ wheel load, $0.69 \mathrm{MPa}$ tire pressure, and $60{ }^{\circ} \mathrm{C}$ temperature, the deformation of OGFC mixture under 8000 times of cyclic load is not more than $5 \mathrm{~mm}$, which indicates that the antirutting performance of the mixture is good. Considering the air void, permeability coefficient, and rutting resistance, it is considered that the aggregate gradation with the median passing rate of $4.75 \mathrm{~mm}$ mesh of $18 \%$ can meet the requirements. Therefore, the grading range in Table 4 is recommended.

2.2. Resilient Modulus Test. Under the unconfined condition, the half sine curve axial stress is applied to the test piece according to a certain temperature and loading frequency, and the recoverable axial strain of the test piece is measured. The resilient modulus of asphalt mixture is the ratio of the stress to the strain.

Firstly, the specimen is crushed at a speed of $2.0 \mathrm{~mm} / \mathrm{min}$ to obtain the compressive strength $\mathrm{P}$ of asphalt mixture. Then, $0.1 \mathrm{kN}$ load is applied to the specimen and preloaded for 50s. The maximum axial stress is $0.1 \mathrm{MPa}, 0.3 \mathrm{MPa}$, $0.5 \mathrm{MPa}, 0.7 \mathrm{MPa}$, and $0.5 \mathrm{MPa}$, respectively. The loading frequency is $10 \mathrm{~Hz}$ and the loading time is $45 \mathrm{~s}$. The load and deformation of the last five waveforms in each case are collected, and the results are drawn on the load deformation curve. The curve is regressed linearly. The slope of the regression equation is the resilient modulus of the mixture. The specimen was formed by the rotary compactor with the size of $\Phi 100 \mathrm{~mm} \times 100 \mathrm{~mm}$ at $15^{\circ} \mathrm{C}$.

2.3. Deformation Performance Test. The deformation characteristic of asphalt mixture is reflected by the creep curve of asphalt mixture. The deformation process of asphalt mixture is observed by applying constant load ( $0.1 \mathrm{MPa}$ in this study) for $1 \mathrm{~h}$ and unloading for $1 \mathrm{~h}$. The curve drawn with time as abscissa and deformation or strain as ordinate is the creep curve of asphalt mixture.

The specimens are kept in a $40^{\circ} \mathrm{C}$ incubator for $2 \mathrm{~h}$ and then are taken out and placed in a $40 \mathrm{C}$ MTS test chamber. A load of $0.2 \mathrm{kN}$ is applied to the specimens for 10 minutes, and then, the specimens are loaded to $0.1 \mathrm{MPa}$ for $1 \mathrm{~h}$ and then unloaded. After $1 \mathrm{~h}$, the experiment is completed, and the deformation of the specimens in the whole process is recorded. 


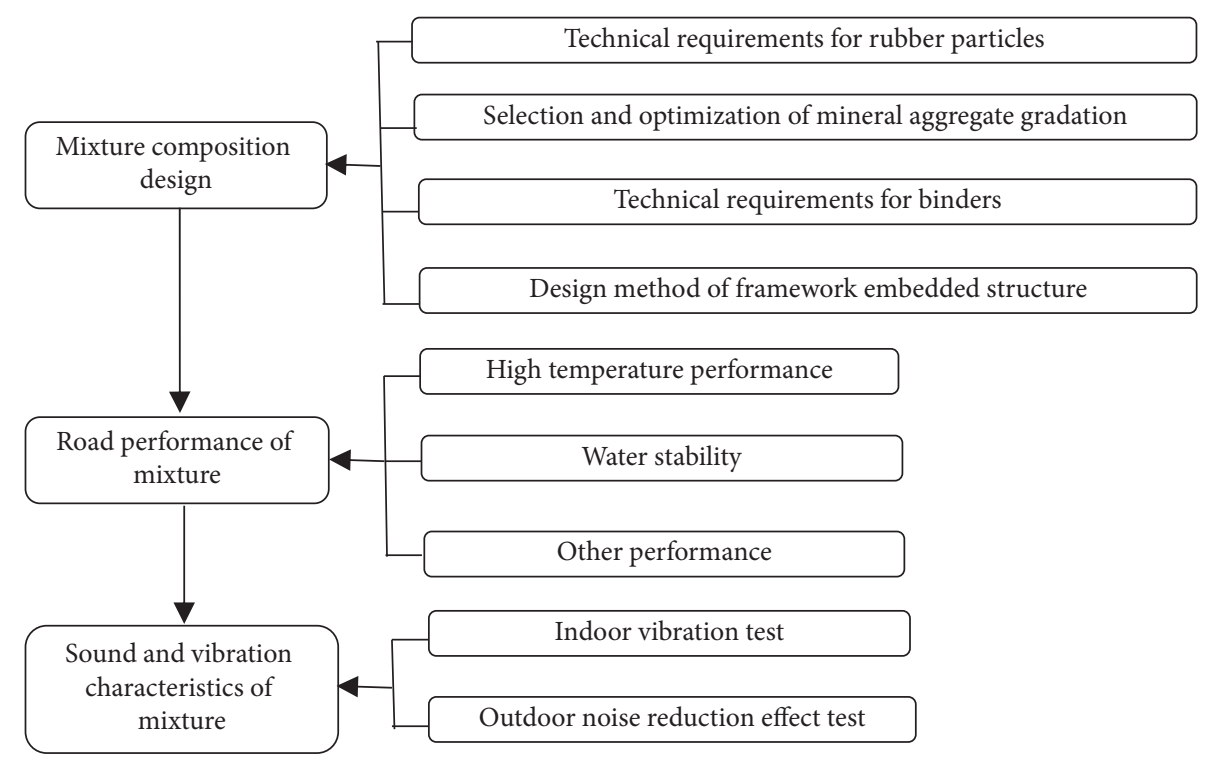

Figure 1: Technology road mapping.

Table 1: Performance requirements and test results of crumb rubber.

\begin{tabular}{|c|c|c|c|c|c|c|c|}
\hline \multirow{2}{*}{ Items } & \multirow{2}{*}{ Slender flat content $(\%)$} & \multirow{2}{*}{ Hardness $(\mathrm{N})$} & \multirow{2}{*}{ Carbon black content (\%) } & \multirow{2}{*}{ Impurity content (\%) } & \multicolumn{3}{|c|}{ Passing ratio $(\%)$} \\
\hline & & & & & $4.75 \mathrm{~mm}$ & $2.36 \mathrm{~mm}$ & $1.18 \mathrm{~mm}$ \\
\hline Test results & 7.8 & 71 & 30.7 & 0.39 & 100 & 94.2 & 5.8 \\
\hline Requirements & $\leq 10$ & $\geq 55$ & $25-38$ & $<0.75$ & 100 & $90-100$ & $0-10$ \\
\hline
\end{tabular}

2.4. Fatigue Performance Test. The fatigue performance of asphalt mixture refers to the number of times it can bear to achieve fatigue failure under the repeated action of certain indirect tensile stress. The test process is as follows: 10 standard Marshall specimens are formed for each mixture ( $\Phi 101.6 \mathrm{~mm} \times 63.5 \mathrm{~mm}$ ) and one of them is taken for indirect tensile test to determine the splitting strength of the mixture. Then, according to the splitting strength, three stress levels of $0.3,0.5$, and 0.7 are determined, and the stress of each stress level is taken as the maximum stress to be applied in the fatigue test. Three specimens are taken to do the fatigue test on MTS machine, and the fatigue life of the specimens under this stress level is obtained. Finally, the stress life curve is drawn to determine the fatigue equation and fatigue parameters. The test temperature is $15^{\circ} \mathrm{C}$, the test frequency is $10 \mathrm{~Hz}$, and the load is half wave sine load without intermittent time. The determination of fatigue life is based on the bending point or failure point on the deformation curve.

2.5. Indoor Vibration Reduction Test. The vehicle tire is used to attenuate the vibration vertically on R-OGFC pavement, respectively, and the transmission characteristics of vehicle vibration are obtained, and the vibration damping effect of the road surface is evaluated. BK noise and vibration analyzer and PC216AX tape recorder are used for the test.

2.6. Noise Reduction Test on Spot. HS5660D precision noise spectrum analyzer was used in the field test, and the maximum sound level $L_{\max }$ in the unit period was detected as the analysis and comparison value. To avoid the adverse effects of environmental noise, the test time is selected in the early hours of the low traffic flows. The test vehicles are Jetta sedan and $12 \mathrm{t}$ heavy-duty liberation truck, respectively, on the road surface of ordinary OGFC and R-OGFC road with crumb rubber (2\%). When testing Jetta car, the height of noise spectrum analyzer is $0.75 \mathrm{~m}$, and the distance from the edge of vehicle track is $6 \mathrm{~m}$. When testing $12 \mathrm{t}$ liberation truck, the height of the noise spectrum analyzer is $1.2 \mathrm{~m}$, and the distance from the driving distance from the edge of the vehicle track is $10 \mathrm{~m}$. The test speed is $30 \mathrm{~km} / \mathrm{h}, 60 \mathrm{~km} / \mathrm{h}$, and $90 \mathrm{~km} / \mathrm{h}$.

\section{Results and Discussion}

3.1. Mix Design. The dense skeleton structure of OGFC makes it different from the dense-graded asphalt concrete in determining the optimal asphalt content. Dense-graded asphalt mixture is a suspended compact structure, and the physical and mechanical characteristics of the mixture, such as strength, density, air voids, and flow value, are closely related to the amount of asphalt mixture. Therefore, the value obtained by the Marshall method can be used to determine the optimal asphalt content accurately. However, the strength of OGFC is mainly formed by the extrusion of coarse aggregate and has little correlation with the asphalt content. Therefore, the optimal asphalt content cannot be determined only by Marshall test, but by the requirements of mixture production, transportation, abrasion resistance, and target air void. The specimens are compacted 50 times on 

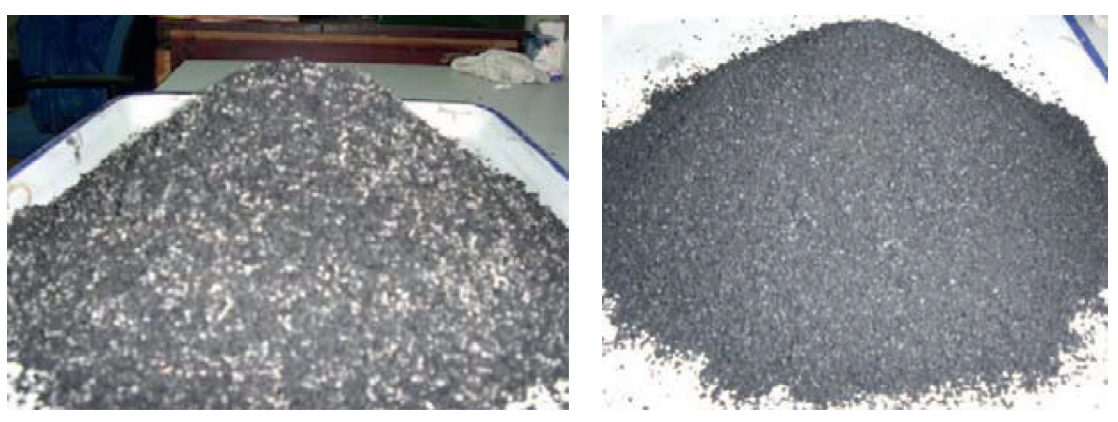

(a)

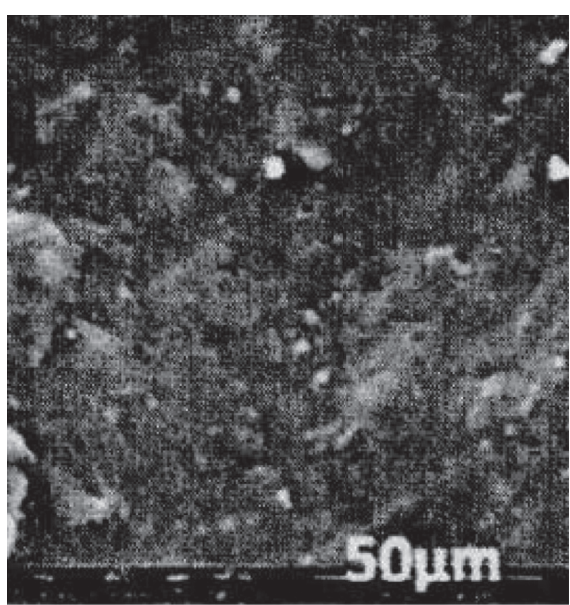

(c)

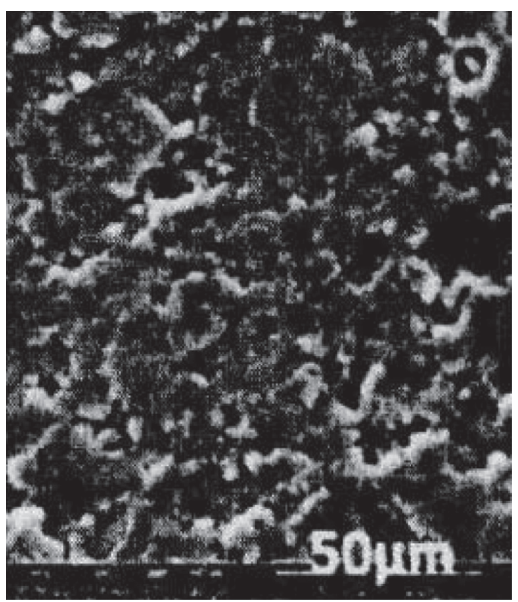

(d)

Figure 2: Crumb rubber sample and scanning electron microscope (SEM). (a) Raw crumb rubber. (b) Treated crumb rubber. (c) Surface texture of raw crumb rubber. (d) Surface texture of treated crumb rubber.

TABle 2: Performance index of 70\# asphalt.

\begin{tabular}{lcccc}
\hline Items & Softening point $/{ }^{\circ} \mathrm{C}$ & Penetration $\left(25{ }^{\circ} \mathrm{C}, 5 \mathrm{~s}, 100 \mathrm{~g}\right) /(0.1 \mathrm{~mm})$ & Ductility $\left(10{ }^{\circ} \mathrm{C}\right) / \mathrm{cm}$ & $\mathrm{Viscosity}\left(135{ }^{\circ} \mathrm{C}\right) /(\mathrm{Pa} \cdot \mathrm{s})$ \\
\hline Test results & 61.4 & 65.6 & 35.2 & 0.27 \\
Requirements & $>46$ & $60-80$ & $>20$ & - \\
\hline
\end{tabular}

TABLe 3: Physical index of aggregate.

\begin{tabular}{lccc}
\hline Stone & Index & Test results & Requirements \\
\hline & Apparent density $\left(\mathrm{g} \cdot \mathrm{cm}^{-3}\right)$ & 2.767 & $\geq 2.50$ \\
& Gross volume density $\left(\mathrm{g} \cdot \mathrm{cm}^{-3}\right)$ & 2.712 & - \\
Coarse aggregate & Crushing value $(\%)$ & 6.5 & $\leq 26$ \\
& Los Angeles attrition rate $(\%)$ & 7.8 & $\leq 28$ \\
Fine aggregate & Flat and elongated particles $(\%)$ & 10 & $\leq 15$ \\
Mineral powder & Water absorption $(\%)$ & 0.8 & $\leq 2.0$ \\
\hline
\end{tabular}

both sides by SGC, and the specimens with $0,1 \%, 2 \%$, and $3 \%$ (mass ratio, i.e., the ratio of crumb rubber mass to aggregate mass) are prepared, as shown in Figure 3.
According to the tests, the optimum asphalt aggregate ratio and related performance indexes of R-OGFC with different crumb rubber contents are calculated (Table 5). 
TABLE 4: OGFC limits of gradation and suggested gradation.

\begin{tabular}{lccccccc}
\hline Sieve size (mm) & 16.000 & 13.200 & 9.500 & 4.750 & 2.360 & 1.180 & 0.300 \\
\hline Midvalue (\%) & 100 & 96 & 59 & 18 & 10 & 8 & 5 \\
Upper limits (\%) & 100 & 100 & 68 & 22 & 13 & 10 & 7 \\
Lower limits (\%) & 100 & 92 & 50 & 14 & 6 & 6 & 4 \\
\hline
\end{tabular}
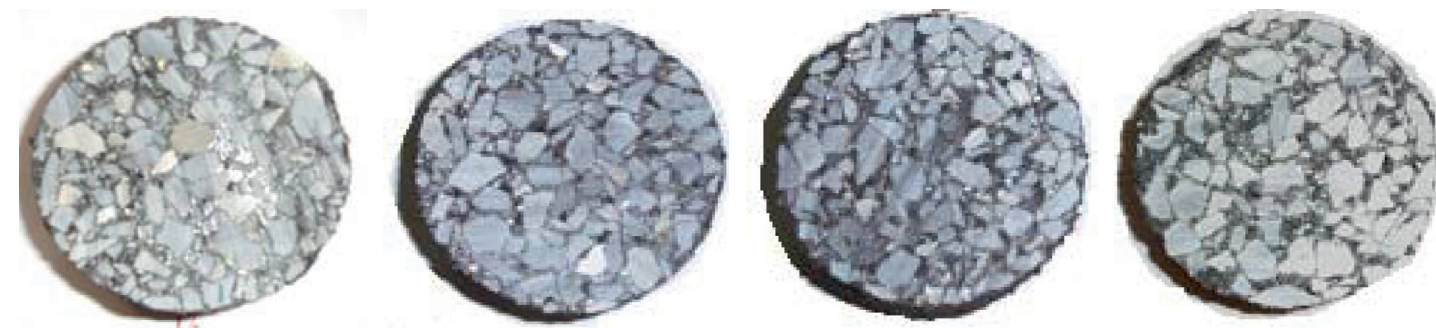

FIgURE 3: R-OGFC specimen profile (the content is $0,1 \%, 2 \%$, and $3 \%$ ).

TABLE 5: Test results of R-OGFC specimen.

\begin{tabular}{lccccccc}
\hline $\begin{array}{l}\text { Rubber content } \\
(\%)\end{array}$ & $\begin{array}{c}\text { Asphalt aggregate ratio } \\
(\%)\end{array}$ & $\mathrm{VV}(\%)$ & $\begin{array}{c}\text { Stability } \\
(\mathrm{kN})\end{array}$ & $\begin{array}{c}\text { DS } \\
\left(\text { times } \cdot \mathrm{mm}^{-1}\right)\end{array}$ & $\begin{array}{c}\text { TSR } \\
(\%)\end{array}$ & $\begin{array}{c}\text { Ratio of leakage } \\
(\%)\end{array}$ & $\begin{array}{c}\text { Ratio of flying loss } \\
(\%)\end{array}$ \\
\hline 0 & 5.2 & 19.1 & 8.1 & 3051 & 83.2 & 0.06 & 9.8 \\
1 & 5.4 & 21.7 & 7.3 & 3572 & 81.6 & 0.02 & 10.3 \\
2 & 5.6 & 21.1 & 6.2 & 5605 & 89.5 & 0.02 & 13.5 \\
3 & 5.8 & 21.5 & 7.4 & 3940 & 83.4 & 0.05 & 14.5 \\
Requirements & - & $18.0 \sim 25.0$ & $>3.5$ & $>3000$ & $>80.0$ & $<0.30$ & $<20.0$ \\
\hline
\end{tabular}

It can be seen that the performance of R-OGFC mixture has been greatly improved after adding rubber particles. With the increase of the content, the mechanical indexes have a certain decline, so the best content is about $2 \%$. At the same time, the air void (VV) of the sample has no change, which indicates that the gradation composition of the mixture is reasonable, and the crumb rubber mixed with the original OGFC mixture form a good skeleton embedded structure. When the rubber particles are added into the mixture, because of the viscosity of the rubber particles themselves, the bonding force between aggregate and asphalt binder at high temperature is increased, and the mechanical properties of the mixture are improved. When the content of rubber particles increases to a certain extent, the volume expansion will destroy the bonding strength between coarse aggregates, and the mixture will develop to a loose state, resulting in the decline of various properties. In particular, because OGFC is a macroporous asphalt mixture, it is mainly used for drainage of pavement structure, so water stability is a very important property. In this study, the freezing-thawing splitting test is used to test the water stability. It can be seen that the freezing-thawing splitting strength ratio (TSR) of R-OGFC meets the requirements, basically ranging from $81.6 \%$ to $89.5 \%$, with little change, showing good water stability.

The grey system theory [25] is used to calculate the influence factors of dry process rubber asphalt mixture strength. The Marshall stability of the mixture is taken as the system mapping quantity, and the related factor is crumb rubber (1, ordinary rubber particles; 2 , modified rubber particles), asphalt (1, ordinary asphalt; 2 , modified asphalt), and gradation (1, gap graded; 2 , open graded). Taking the rubber particle content of $1 \%$ as an example, the stability when the flow value is $5 \mathrm{~mm}$ is selected as the reference sequence, and the correlation coefficient and correlation degree are calculated. The results are shown in Table 6.

According to the calculation results in Table 6, the order of the three influencing factors according to the grey correlation degree is asphalt $>$ gradation $>$ crumb rubber, which indicates that the type of asphalt has the greatest influence on the strength of dry process rubber asphalt mixture. From the correlation degree value, the gradation and asphalt binder are almost equally important, and whether the crumb rubber is modified or not has the least influence on the mixture. This is completely consistent with the experimental results.

3.2. Analysis of Resilient Modulus Test Results. The test results of resilient modulus of mixture with different crumb rubber contents are shown in Figure 4.

It can be seen that, with the increase of crumb rubber content, the resilient modulus of mixture decreases gradually. When the crumb rubber content exceeds $2 \%$, the resilient modulus decreases rapidly. This is mainly because the soft rubber particles with low strength are used in the mixture to replace the original rigid stone, and the overall strength of the mixture becomes smaller. In addition, with the increase of the content of rubber particles, the specimen develops from the original embedded structure to the skeleton loose structure, that is, the skeleton structure of coarse aggregate is crushed by the micelles formed by fine aggregate, mineral powder and asphalt binder, leading to the reduction of the resilient modulus. 
TABLE 6: Results of mixture strength correlation degree and correlation coefficient.

\begin{tabular}{|c|c|c|c|c|c|c|c|c|c|}
\hline Item & & & & Correl & coeffic & & & & Correlation degree \\
\hline Crumb rubber & 1 & 0.712 & 0.774 & 0.434 & 0.333 & 0.369 & 0.410 & 0.622 & 0.582 \\
\hline Asphalt & 1 & 0.712 & 0.338 & 0.514 & 0.802 & 0.650 & 0.410 & 0.622 & 0.631 \\
\hline Gradation & 1 & 0.352 & 0.774 & 0.514 & 0.802 & 0.369 & 0.553 & 0.622 & 0.623 \\
\hline
\end{tabular}

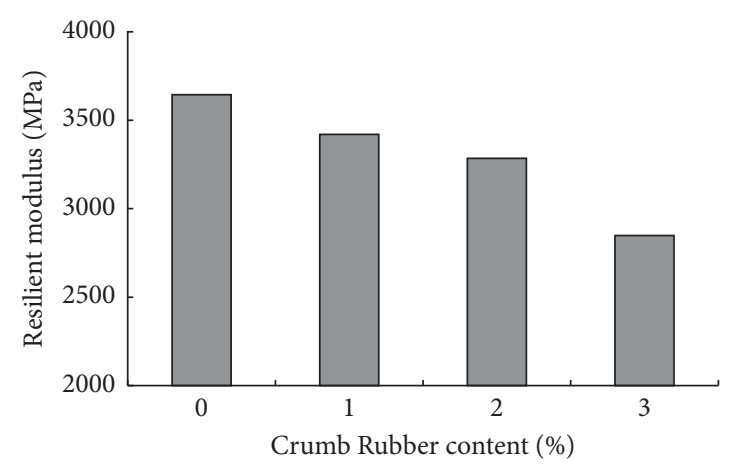

FIGURE 4: Test results of the resilient modulus of R-OGFC.

3.3. Analysis of Deformation Test Results. The creep curve of the mixture with different rubber particle content can be obtained, as shown in Figure 5.

When the content of crumb rubber is 0 , the strain of the specimen is between 0.008 and 0.010 , and when the content of crumb rubber is $3 \%$, the strain of the specimen has reached $0.020-0.030$. When the content of crumb rubber is less than $2 \%$, the total deformation and deformation range are small, and the strain increases obviously when the content increases to $3 \%$. This shows that the rubber particle content should not be too high; otherwise, it will reduce the deformation performance of asphalt mixture. The rubber powder exists in the original state of swelling and still keeps good elasticity of rubber. Under the action of load, the possibility of rigid contact between aggregates is reduced, and the rubber asphalt pavement is more flexible, so it has greater deformation. In addition, the strength of OGFC mixture is mainly controlled by the "bite" between coarse aggregates. The flexible rubber powder fills the voids of the mixture. When the number of rubber particles increases, the coarse aggregate will be squeezed by the micelles formed by asphalt mortar and rubber, and the mixture will gradually become loose structure, which will gradually destroy the bite force between the original coarse aggregate, leading to the decrease of the deformation resistance of the mixture.

3.4. Analysis of Fatigue Test Results. We can get the stress curve of R-OGFC mixture with different crumb rubber contents, as shown in Figure 6.

With the increase of stress ratio, the fatigue life of the mixture decreases exponentially. The mixture without crumb rubber has the best service life, and the fatigue life decreases with the increase of rubber content. It can be seen that the most significant decrease in fatigue life is the specimen without crumb rubber, while the specimen with $3 \%$ rubber powder content decreases the most slowly. This is

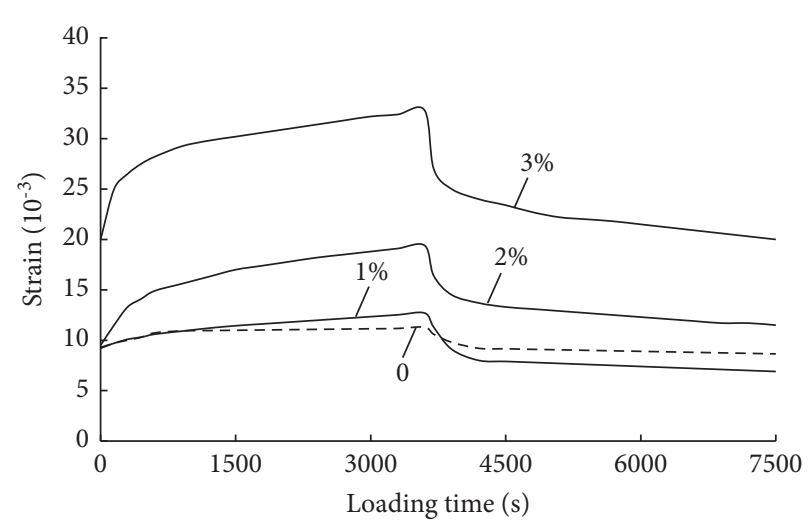

Figure 5: Creep curves of R-OGFC.

because with the increase of the amount of crumb rubber, crumb rubber and aggregate and asphalt fully interact, the damping of the mixture increases, the viscosity increases, and the failure of the specimen is hindered.

Generally, the stress ratio of vehicle load acting on the asphalt surface layer is less than 0.4 . It can be seen that when the crumb rubber content is $0 \%$ and $1 \%$, the fatigue life of the specimens is similar. When the stress ratio is 0.4 , it is 8045 times and 7862 times, respectively. When the content of crumb rubber reaches $2 \%$, the fatigue life index has a certain degree of decline. When the stress ratio is 0.4 , it is 5467 times. When the content of crumb rubber reaches $3 \%$, the fatigue life is only 3523 times. With the increase of rubber particle content, the index of fatigue life decreases greatly. Therefore, to ensure the fatigue life of the specimen, the content of rubber particles should not exceed $2 \%$. This is mainly due to the addition of too much rubber particles; the structure of the mixture develops to the loose state under the long-term load, which leads to the reduction of its fatigue life to a certain extent. 


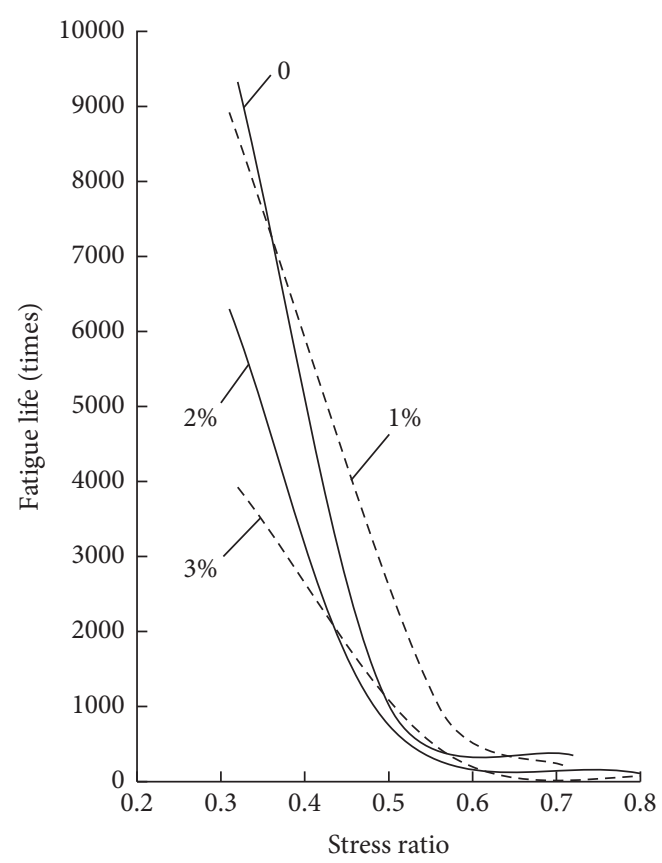

FIgURE 6: Relationship between fatigue life and stress ratio of ROGFC.

3.5. Analysis of Indoor Vibration Test Results. The road vibration attenuation curve of R-OGFC mixture is recorded, as shown in Figure 7 ( $\alpha$ is the acceleration of vibration and $g$ is the acceleration of gravity). Due to the vibration caused by the collision between the tire and the road surface, the tireroad vibration system is simplified to a damped single-degree-of-freedom vibration attenuation model according to particle vibration theory. As can be seen from Figure 7, with the increase of time, the amplitude attenuation gradually decreases, showing a periodic exponential decay law, and finally, the amplitude tends to 0 . Moreover, as time increases, the period of amplitude decay gradually increases to infinity. The vibration attenuation ratio $\xi$ is used as the calculation index to reflect the noise reduction:

$$
\xi=\ln \left(\frac{S_{n}}{S_{n+1}}\right),
$$

where $s$ is the amplitude of vibration attenuation.

The value of $\xi$ (Table 7) can be calculated from Eq. (1). It can be seen that the attenuation ratio of R-OGFC increases and the damping effect is better after adding crumb rubber, but the damping effect gradually decreases when the content of rubber exceeds a certain threshold (2\%).

3.6. Analysis of Noise Reduction Test Results on Spot. The two kinds of vehicles are driving on different roads, and the noise reduction results can be obtained by collecting the detected noise data, as shown in Figure 8.

It can be seen that, with the increase of test vehicle speed, R-OGFC pavement noise reduction effect is more obvious, showing a good noise reduction performance. At the same

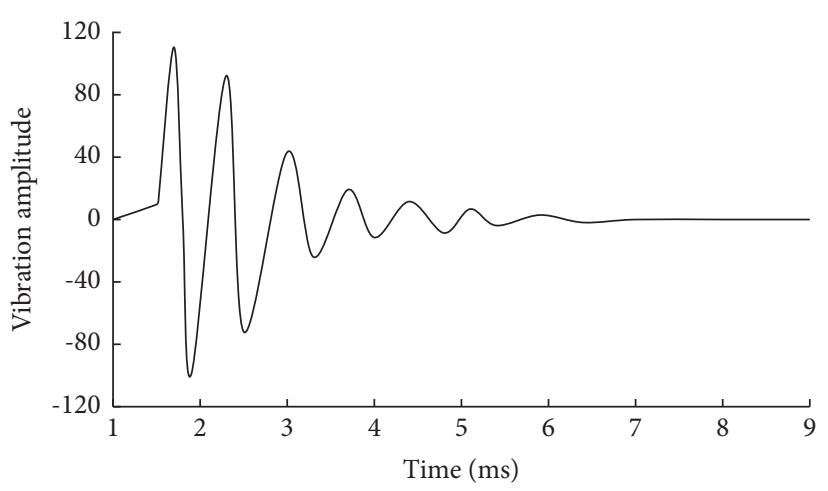

FIgURE 7: Vibration decreased curve of R-OGFC.

TABLE 7: Vibration decreased ratio of R-OGFC.

\begin{tabular}{lc}
\hline Rubber content (\%) & $\xi$ \\
\hline 0 & 0.246 \\
1 & 0.322 \\
2 & 0.447 \\
3 & 0.269 \\
\hline
\end{tabular}

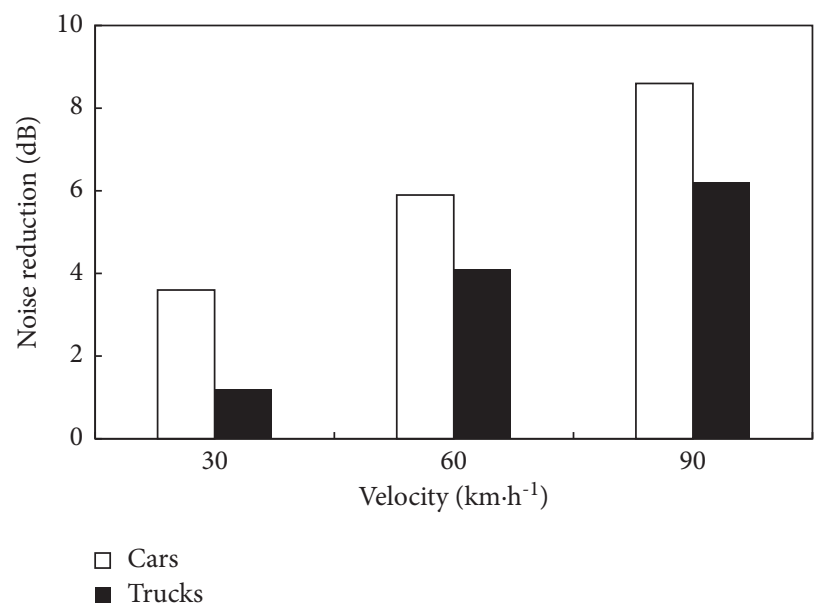

Figure 8: Noise reduction results of cars and trucks.

speed, the noise reduction effect of car is $2 \sim 3 \mathrm{~dB}$ better than that of truck. The faster the driving speed is, the more significant the noise reduction effect is.

When the attenuation of air is not considered, the vehicle noise can be regarded as a point sound source under the condition of free sound field (free space), and its sound wave follows the law of spherical divergence. According to the sound power as the evaluation quantity of point sound source, the attenuation adopts

$$
\Delta L=10 \log \left(\frac{1}{4} \pi r^{2}\right),
$$

where $\Delta L$ is the attenuation value due to distance increase $(\mathrm{dB})$ and $r$ is the distance from the point sound source to the sound receiving point $(\mathrm{m})$.

For the same point sound source, the attenuation values of different distances can be calculated by 


$$
\Delta L=20 \log \left(\frac{r_{2}}{r_{1}}\right)
$$

where $r_{1}$ and $r_{2}$ is the distance between different sound source points $(\mathrm{m})$.

According to equation (3), it can be calculated that every $6 \mathrm{~dB}$ of noise attenuation is equivalent to twice the noise distance. According to the test results in Figure 8, it can be seen that the noise reduction of the car reaches $8.68 \mathrm{~dB}$ at the driving speed of $90 \mathrm{~km} / \mathrm{h}$, which is equivalent to 2.7 times longer noise distance. When the heavy truck runs at $90 \mathrm{~km} /$ $\mathrm{h}$, the noise reduction reaches $6.28 \mathrm{~dB}$, which is equivalent to 2.1 times longer noise distance. It can be considered that the noise reduction effect of R-OGFC pavement is significant after adding crumb rubber.

\section{Conclusion}

(1) The special gradation and mix proportion design of R-OGFC mixture modified by rubber particles are carried out. The test results show that the air void of the mixture changes little, indicating that the gradation used better accommodates rubber particles. The performance of the modified mixture is greatly improved; especially, the dynamic stability index is increased by $0.2-0.8$ times.

(2) Through the tests on the resilient modulus, fatigue performance, and deformation performance of R-OGFC mixture with different crumb rubber content, it can be found that the three indexes have different degrees of reduction, the reduction range is $10 \%-37 \%$, and the reduction range becomes larger with the increase of rubber particle content. Therefore, the amount of rubber powder should not be too high, so as not to affect the road performance.

(3) According to the indoor vibration test, it can be determined that when the crumb rubber content is $2 \%$, the R-OGFC pavement vehicle sound attenuation ratio is the largest, and the noise reduction effect is the most obvious. Through the test on spot, the car and heavy truck drive on the road before and after the rubber powder modification, respectively, and the noise reduction reaches $8.6 \mathrm{~dB}$ and $6.2 \mathrm{~dB}$, which has a good noise reduction effect.

\section{Data Availability}

All data used to support the findings of this study are available from the corresponding author upon reasonable request.

\section{Conflicts of Interest}

The authors declare that they have no conflicts of interest.

\section{Authors' Contributions}

Ya Wang engaged in the research of pavement materials; Xianguang Wang engaged in material research and development; Liwen Zhang engaged in research of road materials.

\section{Acknowledgments}

This study was funded by the National Key Research and Development Program (Grant no. 2016YFE0204800).

\section{References}

[1] Q. Liu, J. Xie, and Z. Zhang, "A vehicle fuel consumption model on reconstructed roads based on the roughness and its measurement method," Advances in Civil Engineering, vol. 2021, Article ID 8812376, 7 pages, 2021.

[2] M. M. Rahman, G. D. Airey, and A. C. Collop, "Moisture susceptibility of high and low compaction dry process crumb rubber modified asphalt mixtures," Journal of the Transportation Research Board, vol. 2180, pp. 121-129, 2002.

[3] F. P. Xiao, T. Wang, and J. Y. Wang, "Mechanism and research development of noise reduction technology of rubberized asphalt pavement," China Journal of Highway and Transport, vol. 32, pp. 73-91, 2019.

[4] S. Bilawchuks, "Tire noise assessment of asphalt rubber crumb pavement," Canadian Acoustics, vol. 33, pp. 37-41, 2005.

[5] X. J. Wen and Q. Yang, "Study on the quiet pavement with SMA including coarse crumb-rubber," Journal of Building Materials, vol. 11, pp. 230-234, 2008.

[6] N. Xu, Y. Xu, and Y. X. Ding, "Study on sound absorption characteristics of rubber material," Technical Acoustics, vol. 8, pp. 45-51, 2011.

[7] B. Philip, J. K. Abraham, V. K. Varadan, V. Natarajan, and V. G. Jayakumari, "Passive underwater acoustic damping materials with Rho-C rubber-carbon fiber and molecular sieves," Smart Materials and Structures, vol. 13, no. 6, pp. N99-N104, 2004.

[8] G. Q. Wu, H. Yan, and H. Y. Xia, "Study on the sound absorption performance of single layer structure metal rubber Material," Rare Materials and Engineering, vol. 39, pp. 1923-1927, 2010.

[9] L. Wang, B. L. Wang, and Y. M. Xing, "Experimental study on sound absorption of crumb rubber modified asphalt mixture with large porosity," Engineering Mechanics, vol. 26, pp. 181-184, 2009.

[10] W. Cao, "Study on properties of recycled tire rubber modified asphalt mixtures using dry process," Construction and Building Materials, vol. 21, no. 5, pp. 1011-1015, 2007.

[11] M. Bueno, J. Luong, F. Terán, U. Viñuela, and S. E. Paje, "Macrotexture influence on vibrational mechanisms of the tyre-road noise of an asphalt rubber pavement," International Journal of Pavement Engineering, vol. 15, no. 7, pp. 606-613, 2014.

[12] V. Chandran, L. Nagarajan, and M. R. Thomas, "Evaluation of vibration damping behavior of different sizes of waste tyre rubber in natural rubber composites," Journal of Composite Materials, vol. 52, pp. 1-15, 2018.

[13] S. Meiarashi, M. Ishida, T. Fujiwara, M. Hasebe, and T. Nakatsuji, "Noise reduction characteristics of porous elastic road surfaces," Applied Acoustics, vol. 47, no. 3, pp. 239-250, 1996.

[14] F. Kehagia and S. Mavridou, "Noise reduction in pavement made of rubberized bituminous top layer," Open Journal of Civil Engineering, vol. 4, no. 3, pp. 198-208, 2014.

[15] Y. M. Yang, Z. M. Wang, and J. M. Ge, "Primary study of acoustics and vibration feature on stone mastic asphalt pavements," Journal of Tongji University, vol. 31, pp. 370-373, 2013. 
[16] W. H. Shang and J. Li, "Surface modification of ground tire rubber and its adhesion property," Polymer Materials Science and Engineering, vol. 34, pp. 99-104, 2018.

[17] S. Poovaneshvaran, M. R. Mohd Hasan, and R. Putra Jaya, "Impacts of recycled crumb rubber powder and natural rubber latex on the modified asphalt rheological behaviour, bonding, and resistance to shear," Construction and Building Materials, vol. 234, pp. 117357-117375, 2020.

[18] M. R. Hainin, P. J. Ramadhansyah, T. H. Chan, A. H. Norhidayah, and F. M. Nazri, "Strength and properties of concrete pavement incorporating multiple blended binders," Materials Science Forum, vol. 889, pp. 265-269, 2017.

[19] F. Moreno, M. C. Rubio, and M. J. Martinez-echevarria, "Analysis of digestion time and the crumb rubber percentage in dry-process crumb rubber modified hot bituminous mixes," Construction and Building Materials, vol. 25, no. 5, pp. 2323-2334, 2011.

[20] M. Yu and G. X. Wu, "Research on the mix design of dry process crumb rubber modified asphalt mixture," Journal of Building Materials, vol. 17, pp. 100-105, 2014.

[21] R. B. Ren, L. T. Geng, and Q. Xu, "Performance of reclaimed rubber-plastic modified asphalt and its mixture," Journal of Building Materials, vol. 19, pp. 1092-1096, 2016.

[22] T. Bennert, D. Hanson, and A. Maher, "Influence of pavement surface type on tire/pavement generated noise," Journal of Testing and Evaluation, vol. 33, pp. 94-100, 2005.

[23] F. M. Tehrani, "Noise abatement of rubberized hot mix asphalt: a brief review," International Journal of Pavement Research \& Technology, vol. 8, pp. 58-61, 2015.

[24] M. Wang, F. Shang, D. Hu, Z. Hao, and B. Gao, "Characteristics and strength mechanisms of gussasphalt based on the Mohr-Coulomb theory," Emerging Materials Research, vol. 8, no. 4, pp. 721-728, 2019.

[25] S. F. Liu, Y. G. Dang, and Z. G. Fang, Grey System Theory and its Application, Science Press, Beijing China, 3rd edition, 2004. 